\title{
EFFECT OF WHISKERS AND SMALL PARTICLES ON THE DEFOR- MATION AND RECRYSTALLIZATION TEXTURE OF ALUMINIUM
}

\author{
N. Hansen, D. Juul Jensen and Y.L. Liu \\ Materials Department, Ris $\emptyset$ National Laboratory, DK-4000 Roskilde, Denmark
}

\begin{abstract}
The effect of small $\mathrm{Al}_{2} \mathrm{O}_{3}$ particles $(\mathrm{d}<0.1 \mu \mathrm{m})$ and of a mixture of $\mathrm{Al}_{2} \mathrm{O}_{3}$ particles and $\mathrm{SiC}$-whiskers on the cold-rolling and on the recrystallization texture of aluminium has been studied by neutron diffraction. It has been osberved that the strength and the relative intensity of the main rolling components in the deformation texture are affected both by small particles and by introduction of $\mathrm{SiC}$ whiskers. In the recrystallized state very different textures have been found ranging from a weak cube texture to a strong $\{100\}<013>(\mathrm{N}$-texture). The measured textures are related to the size of the recrystallized grains in a discussion of the effect of small particles and whiskers on deformation microstructures and nucleation and growth processes.
\end{abstract}

\section{INTRODUCTION}

Large particles (diameter $>0.1-1 \mu \mathrm{m})$ and small particles $(<0.1 \mu \mathrm{m})$ affect the deformation and recrystallization texture of aluminium both when they are present separately or as a mixture ${ }^{1-4}$. This effect is important to many conventional aluminium alloys but also to the newly developed metal-matrix composite containing large particles or whiskers. Furthermore many advanced processes (e.g. mechanical alloying, spray deposition and rapid solidification) produce alloys containing both large and small particles.

In the present study the base materials were two aluminium alloys containing different volume fractions of small $\mathrm{Al}_{2} \mathrm{O}_{3}$ particles. The materials were produced by a powder consolidation route allowing $\mathrm{SiC}$-whiskers to be added, thus mixtures of small particles and whiskers could be investigated. The materials were cold-rolled and recrystallized and textures were measured in both states. Finally the recrystallized grain size was measured and related to the nucleation and growth processes taking place during recrystallization.

\section{EXPERIMENTAL}

Four different starting materials were produced on basis of aluminium powder of commercial purity by powder blending and consolidation ${ }^{5}$. The main particle/whisker parameters are given in table 1 . The oxide particles were platelets with mean equivalent 
spherical diameters in the range 54 to $82 \mathrm{~nm}^{5}$. The $\mathrm{SiC}$ whiskers were $\beta$-type single crystals, $0.1-1 \mu \mathrm{m}$ in diameter and $30-100 \mu \mathrm{m}$ in length. During processing the whiskers were fragmented and on average their length was reduced to $2 \mu \mathrm{m}$. After consolidation about 60 and 80 vol\% of the whiskers in the MD105 and MD201 material, respectively were present in clusters with sizes ranging from 0.5 to $5 \mu \mathrm{m}$. After consolidation the materials were cold rolled and recrystallized. For the texture measurements the recrystallized materials were cold rolled to $90 \%$ reduction in thickness and furnace annealed to complete recrystallization. It has to be noted that the strength but not the type of the recystallization textures are strongly influenced by the heating rate and annealing temperature. This is described in detail elsewhere in these proceedings ${ }^{6}$. The textures are presented by ODFs calculated according to the series expansion method. $\lambda \leq 22$ and only even terms are included in the calculations.

Table 1. Materials parameters

\begin{tabular}{|l|c|c|c|}
\hline Material & $\begin{array}{c}\mathrm{Al}_{2} \mathrm{O}_{3} \\
\text { vol\% }\end{array}$ & $\begin{array}{c}\mathrm{SiC} \\
\text { vol\% }\end{array}$ & $\begin{array}{c}\text { SiC in clusters } \\
\%\end{array}$ \\
\hline MD201 & 0.6 & 0 & 0 \\
MD201 + SiC & 0.6 & 2 & 80 \\
MD105 & 0.8 & 0 & 0 \\
MD105 + SiC & 0.8 & 2 & 60 \\
\hline
\end{tabular}

RESULTS

\section{Deformation Textures}

The deformation textures of the 4 materials are shown in Fig. 1. All textures are of the copper type rolling texture, but with significant variations in the intensities of the main components (Br: $\{110\}<112>$, S: $\{123\}<634>$, Cu: $\{112\}<111>$ ). For the unreinforced materials an increase in the $\mathrm{Al}_{2} \mathrm{O}_{3}$ content results in a strengthening of the $\mathrm{S}$ component whereas the $\mathrm{Br}$ and $\mathrm{Cu}$ components are almost unchanged (compare Fig. 1a and b). Besides the $\mathrm{S}$ also the $\mathrm{Cu}$ component strengthens with increasing $\mathrm{Al}_{2} \mathrm{O}_{3}$ content in the reinforced materials (compare Fig. 1c and d). The SiC also significantly changes the intensity distributions of the deformation textures. For both material MD201 and MD105 the presence of SiC causes a weakening of the $\mathrm{Br}$ and the $\mathrm{S}$ component, whereas, the $\mathrm{Cu}$ component is almost unaffected of SiC in MD201 and strengthens with $\mathrm{SiC}$ in MD105.

\section{Recrystallization Textures}

The recrystallization textures are shown in Fig. 2. As can be seen, they are of different types. The MD201 recrystallization texture is a weak cube texture with no retained rolling or other significant components. The ODF for the MD105 material reflects the large recrystallized grain size $(\sim 500 \mu \mathrm{m})$ and is thus composed of single sharp peaks. The main component is close to the cube component, however, due to the grain size problem, the peak intensities cannot be used to evaluate the strength of the texture. This problem will be solved by using a larger sample size for the future neutron texture measurements of this sample. When $\mathrm{SiC}$ whiskers are present, the type of the recrystallization texture changes. In MD201 + SiC retained rolling components and components in a broad angular range (full with half maximum $\sim 65^{\circ}$ along $\varphi 1$, and $\sim 18^{\circ}$ 


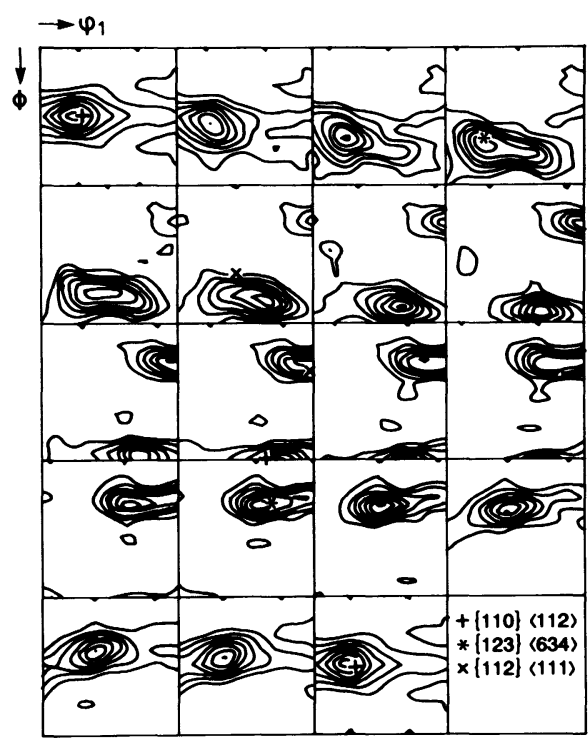

Levels $1,2,3, \ldots . . \quad \varphi_{2}$ sections $0,5, \ldots \ldots \ldots, 9^{\circ}$

a)

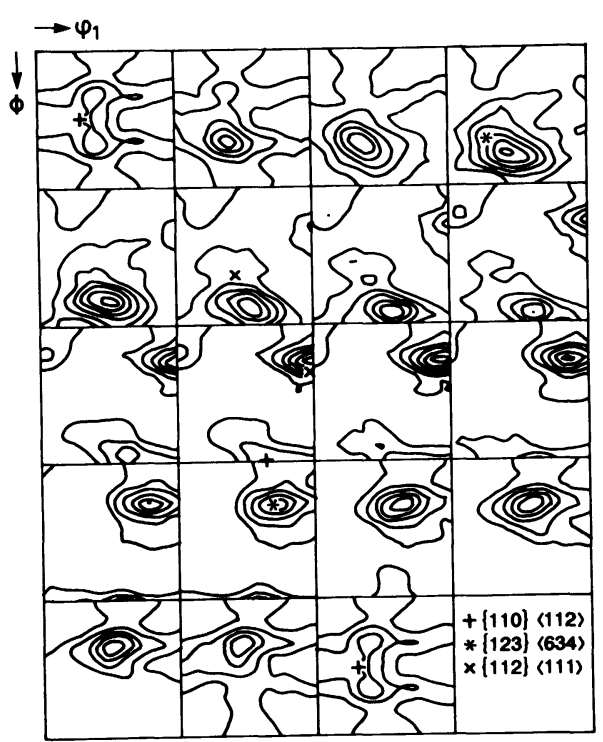

Levels $1,2,3, \ldots . . \quad \varphi_{2}$ sections $0,5, \ldots \ldots \ldots ., 90^{\circ}$

c)

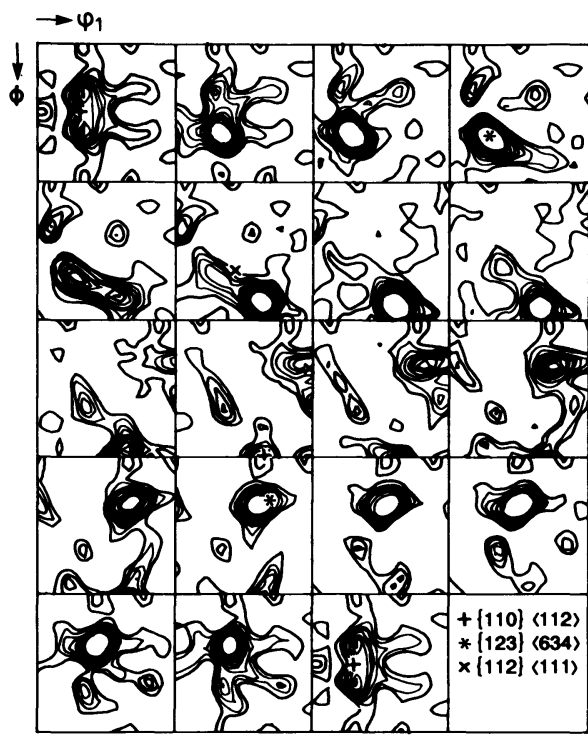

Levels $1,2,3, \ldots . . \quad \varphi_{2}$ sections $0,5, \ldots \ldots \ldots . ., 90^{\circ}$

b)

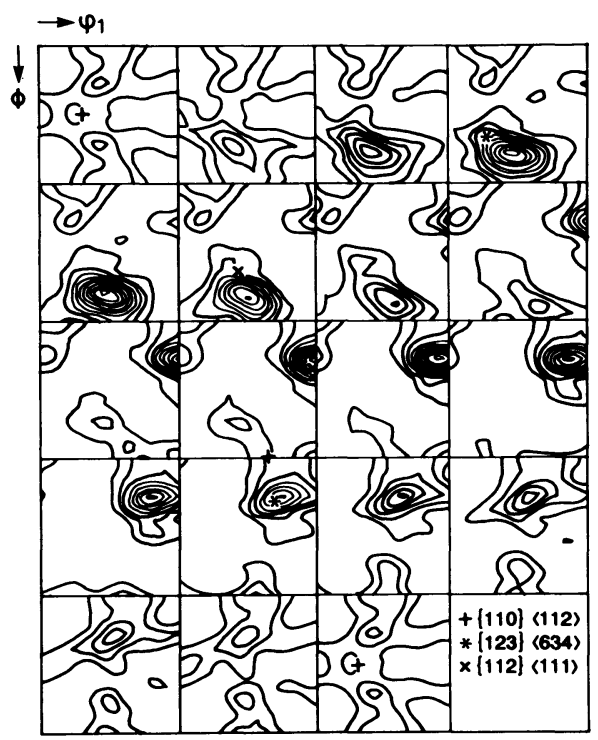

Levels $1,2,3, \ldots . . \quad \varphi_{2}$ sections $0,5, \ldots \ldots \ldots . ., 90^{\circ}$

d)

Fig. 1. Deformation textures. a) MD201. b) MD105. c) MD201 + SiC. d) MD105 + SiC. 


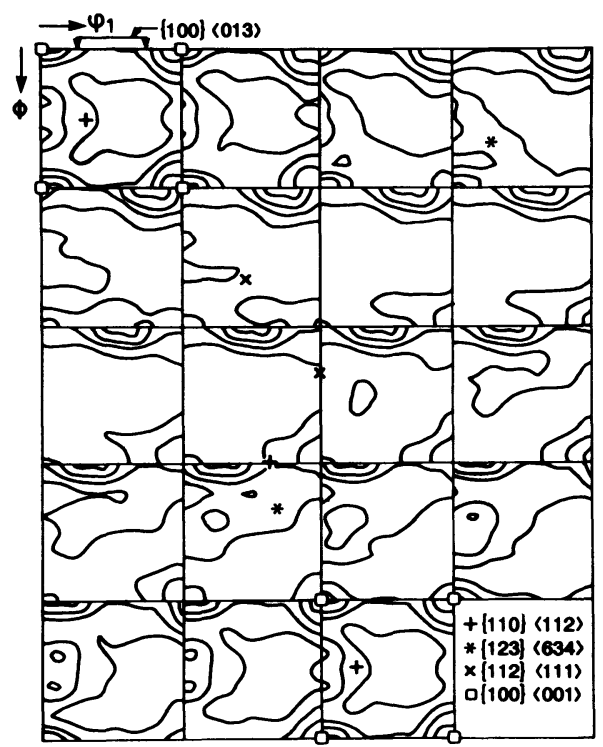

Levels $1,2,3, \ldots$. .

$\varphi_{2}$ sections $0,5 \ldots . ., 90^{\circ}$ a)

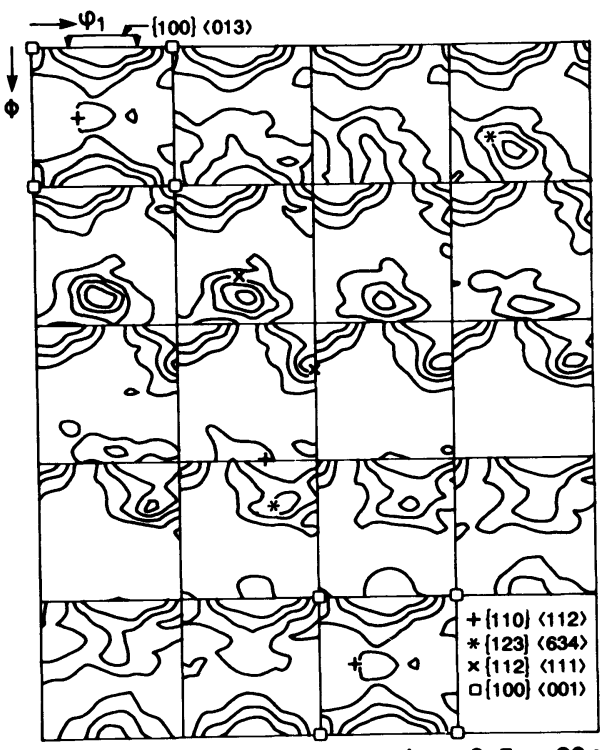

Levels $1,2,3, \ldots .$. $\varphi_{2}$ sections $0,5 \ldots . ., 90^{\circ}$

c)

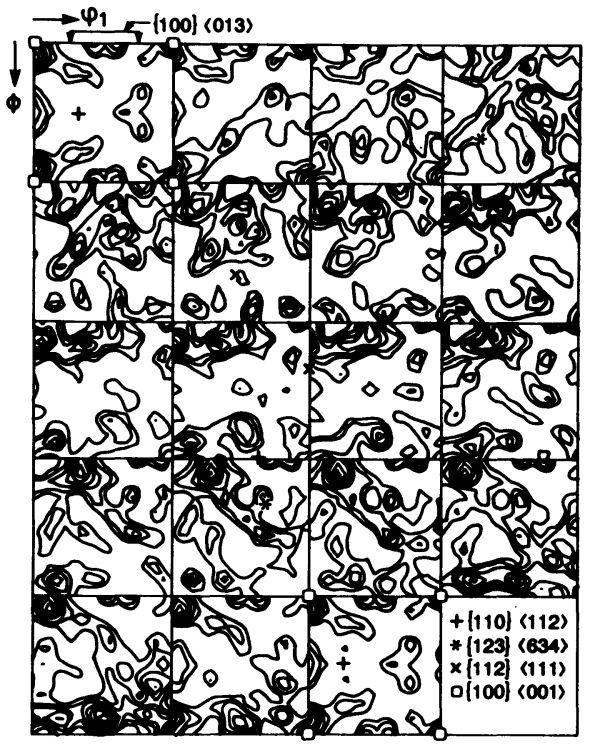

Lovels $1,2,3, \ldots .$.

$\varphi_{2}$ sections $0,5 \ldots . . ., 90^{\circ}$

b)

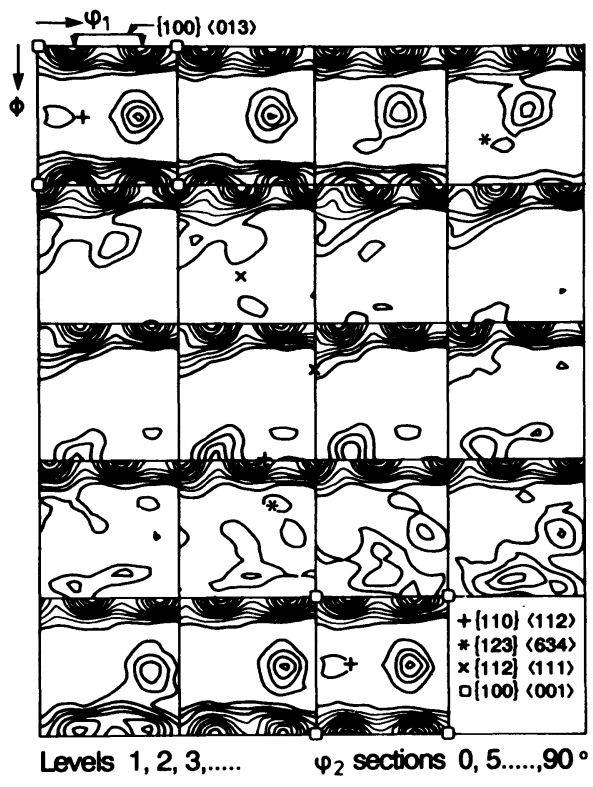

d)

Fig. 2. Recrystallization textures. a) MD201. b) MD105.

c) MD201 + SiC. d) MD105 + SiC. 
along $\phi)$ around $\{100\}<011>$ are dominating. The texture is rather weak with a maximum intensity of $4.5 \mathrm{x}$ random. The recrystallization texture in MD105 $+\mathrm{SiC}$ is a strong rotated cube texture with maxima at $\{100\}<013>$ (the $N$ component). There is almost no retained rolling texture and only a weak peak ( $2 \times$ random) close to $\{110\}<332>$ is observed.

\section{Recrystallized grain size}

The grain sizes in the recrystallized state are given in Table 2. In agreement with earlier observations ${ }^{5}$ it has been found that addition of $\mathrm{Al}_{2} \mathrm{O}_{3}$ particles gives a relatively coarse recrystallized grain size which is reduced by the addition of SiC whiskers. It should be noted that in MD201 containing SiC the grain size distribution is bimodal containing small grains (mean grain size $2.8 \mu \mathrm{m}$ ) and relatively large grains (mean grain size $140 \mu \mathrm{m})$.

Table 2. Grain sizes

\begin{tabular}{|ll|c|}
\hline & & Mean grain size $(\mu \mathrm{m})$ \\
\hline MD201 & starting material & $518 \pm 26$ \\
& recrystallized $\left(90 \% \mathrm{cr}, 350^{\circ} \mathrm{C}\right)$ & $186 \pm 10$ \\
\hline MD201 $+2 \% \mathrm{SiC}$ & starting material & $162 \pm 11$ \\
& recrystallized $\left(90 \% \mathrm{cr}, 400^{\circ} \mathrm{C}\right)$ & $140 \pm 5$ \\
& & $2.8 \pm 2$ \\
\hline MD 105 & starting material & $1116 \pm 113$ \\
& recrystallized $\left(90 \% \mathrm{cr}, 493^{\circ} \mathrm{C}\right)$ & $443 \pm 59$ \\
\hline MD105 $+2 \%$ SiC & starting material & $560 \pm 42$ \\
& recrystallized $\left(90 \% \mathrm{cr}, 355^{\circ} \mathrm{C}\right)$ & $236 \pm 9$ \\
\hline
\end{tabular}

\section{DISCUSSION}

Earlier studies ${ }^{2,4}$ have shown that the introduction of small particles may strengthen the rolling texture whereas introduction of large particles may have the opposite effect. The reasons given are a) that small particles may homogenize the deformation pattern thereby reducing the amount of structural inhomogeneities which can cause a spread in the texture and b) that coarse particles may be the origin of local lattice rotations ${ }^{7}$ thereby causing a spread in the texture. This general trend is observed in the present study if the sum of the intensities of the main texture components is compared. However, the strengthening and weakening effects of small particles and whiskers respectively, is not observed when the main components are considered separately. The results therefore indicates that the effect of small particles and whiskers on the deformation pattern may affect the development of the main texture component differently. A further study of such an effect will require a simultaneous analysis of microstructure and microtexture ${ }^{8}$.

The recrystallization texture in the materials containing only $\mathrm{Al}_{2} \mathrm{O}_{3}$ is dominated by the cube component but the MD201 texture is fairly weak indicating that many of grains have random orientations. The principal nucleation sites in these materials are 
intergranular sites (transition bands), original grain boundaries and the intermetallic $\mathrm{FeAl}_{3}$ particles being present in the as-delivered aluminium powder ${ }^{9}$. Nucleation at transition bands and original grain boundaries is expected to give cube texture and retained rolling texture respectively after recrystallization, whereas nucleation at $\mathrm{FeAl} 3$ particles may result in a spread rolling or a random texture ${ }^{4}$. That the retained rolling component is not observed in the recrystallization texture may be related to the relative coarse starting grain sizes (see table 2), i.e. nucleation at the other sites (transition bands and $\mathrm{FeAl}_{3}$ particles) dominates.

In $\mathrm{Al}_{-} \mathrm{Al}_{2} \mathrm{O}_{3}$ materials containing $\mathrm{SiC}$ whiskers the nucleation is retarded by the $\mathrm{Al}_{2} \mathrm{O}_{3}$ particles and accelerated by the SiC whiskers ${ }^{5}$. The nucleation rate will therefore be largest in the MD201 material explaining the large concentration of relatively small grains (see table 2). The principal nucleation sites in these materials are SiC clusters, single $\mathrm{SiC}$ whiskers, $\mathrm{FeAl} 3$ particles and original grain boundaries. Transition bands are not operating since almost no bands develop during rolling of the $\mathrm{SiC}$ containing materials ${ }^{5}$. Compared to the materials without $\mathrm{SiC}$, the importance of original grain boundaries as nucleation sites is increased due to the smaller starting grain sizes. Preliminary microtexture measurements of nuclei developed at $\mathrm{SiC}$ clusters show that the nuclei have a wide range of orientation out of which some are close to $\{100\}<013>$. Single $\mathrm{SiC}$ whiskers are expected to act as the large $\mathrm{FeAl} 3$ particles and give spread rolling or random texture. For MD201 + SiC the retained rolling texture therefore may have its origin at $\mathrm{SiC}$ whiskers, $\mathrm{FeAl}_{3}$ particles and grain boundary sites. The broad $\{100\}<011>$ component probably develops as a combination of nucleation at the above mentioned sites $(\{100\}<011>$ is a component of the rolling texture) and at $\mathrm{SiC}$ clusters which may explain the broadening towards $\{100\}<013>$. For MD105+ SiC, the larger oxide content reduces the nucleation density and only the most potential sites develop into nuclei. That the recrystallization texture in this case is a strong $\{100\}<013>$ texture seems qualitatively to agree with the observation that $\{100\}<013>$ nuclei may develop at SiC clusters which are surrounded by very complex deformation zones containing high angle boundaries and therefore are preferential nucleation sites. However, further investigation are needed, to fully explain the difference between the two materials containing $\mathrm{SiC}$ whiskers.

\section{REFERENCES}

1. N. Hansen and D. Juul Jensen, In "Formability and Metallurgical Structures", A.K. Sachdev and J.D. Embury eds. (The Metallurgical Society AIME 1986), p.119.

2. D. Juul Jensen, N. Hansen, F.J. Humphreys, 8th Int. Conf. on Textures of Materials, J.S. Kallend and G. Gottstein eds. (The Metallurgical Society AIME 1988) p.431.

3. O. Engler, J. Hirsch and K. Lücke, Acta Metall., 37, 2743 (1989).

4. N. Hansen and D. Juul Jensen, in "Recrystallization '90", 1990, Australia.

5. Y.L. Liu, N. Hansen and D. Juul Jensen, Metall. Trans. A, 20A, 1743, (1989).

6. D. Juul Jensen and N. Hansen, These proceedings.

7. F.J. Humphreys, Metallurgical Forum 12, 123 (1978).

8. F.J. Humphreys, Textures and Microstructures 6, 45 (1983).

9. N. Hansen and B. Bay, Acta Metall., 29, 65 (1981). 